\title{
A UTILIZAÇÃO DAS FERRAMENTAS DA QUALIDADE NA RETENÇÃO DE ALUNOS NOS CURSOS DE ENSINO A DISTÂNCIA
}

\author{
CURITIBA/PR MAIO/2018
}

\author{
Alcimar Roberto Kowalski - (1491) CENTRO UNIVERSITÁRIO INTERNACIONAL - UNINTER - \\ kowalski0010@gmail.com \\ João Augusto Mattar Neto - (1491) CENTRO UNIVERSITÁRIO INTERNACIONAL - UNINTER - \\ joaomattar@gmail.com \\ Lílian Soares Alves Branco - UNILASALLE - lilian.sab@gmail.com
}

Tipo: Relato de Experiência Inovadora (EI)

Categoria: Suporte e Serviços

Setor Educacional: EDUCAÇÃO SUPERIOR

\begin{abstract}
RESUMO
Este artigo apresenta um estudo no auxílio da competitividade e na melhoria para a retenção de alunos na Educação a Distância, pois observa-se que cada vez mais as organizações despendem forças para alterações em seus processos produtivos ou na prestação de seus serviços. E para a área educacional este fator cumpre um importante papel. Um dos principais objetivos na área de ensino é fazer com que seu público se mantenha fiel do início ao fim dos programas propostos. Assim sendo, para a Educação a Distância, não seria diferente. E como o tema fidelidade encaminha-se para a evasão do público alvo, a proposta é apresentar alternativas na redução deste problema, com a utilização de algumas ferramentas da qualidade. Um problema de qualidade pode ser tradicionalmente definido como um gap entre o estado atual e o estado desejado, ou seja, um resultado inesperado do processo que necessita ser melhorado (SMITH, 1998). E a correta gestão dos processos envolvidos, sejam eles na produção ou a prestação de serviços, compreende melhorar o alcance das metas com a utilização de metodologias eficazes que auxiliam a organização na busca em equilibrar ou reduzir seus problemas, o que é essencial para a maximização dos resultados e consequente aumento da competitividade.
\end{abstract}

Palavras-chave: EaD, Retenção, Ferramentas da Qualidade, Critérios na evasão 


\section{INTRODUÇÃo}

Existem hoje no Brasil um grande número de Instituições atuando no Ensino a Distância $(\mathrm{EaD})$, através dos vários cursos ofertados e das diferentes metodologias de ensino, pois a comodidade de aprender em qualquer lugar é um dos principais motivos da existência destes cursos, já que o perfil de estudante que temos hoje é outro, o que requer um perfil dinâmico e interativo através do uso das ferramentas de comunicação e informação no desenvolvimento do seu processo de ensino e aprendizagem.

Porém, apesar da EaD apresentar uma série de vantagens, ainda não é o suficiente para diminuir os índices de evasão, pois o fenômeno da evasão é causado por diferentes razões, seja por questões pessoais do estudante, ou até mesmo provocado por fatores institucionais. Iremos considerar como uma das hipóteses para evasão no ensino a distância, a falta de qualidade ou um serviço de tutoria insuficiente na prestação de serviços, na qual precisa melhorar a comunicação, ou seja, precisa buscar desenvolver uma comunicação mais efetiva e próxima dos estudantes, contando com o apoio de ferramentas na mensuração da qualidade, que permita o controle e registro desses contatos, na tentativa de solucionar os problemas advindos da falta de comunicação existente entre o serviço de tutoria e os estudantes.

Vale mencionar uma importante observação sobre evasão e a retenção, como uma ligeira escapada do formato dos capítulos de livros acadêmicos, mas de forma muito sucinta que captura a riqueza de conhecimento de dois dos pesquisadores mais experientes do mundo em educação a distância. Alan Woodley e Ormond Simpson (ambos recentemente aposentados da Open University do Reino Unido) se envolvem em uma conversa centrada sobre o "elefante na sala da educação a distância": evasão dos estudantes, baixas taxas de conclusão ou persistência. A conversa revela os fatos brutais (escondidos, como muitas vezes o são por instituições relutantes), razões para a indiferença lamentável de todos os atores - incluindo os próprios alunos. (ZawackiRichter, 2015)

E esse fenômeno da evasão é uma realidade fortemente presente no Ensino a Distância, conforme dados do Censo apresentados pelo INEP em 2015, observamos milhões de matrículas, porém um percentual baixo de concluintes no ensino superior. 


\begin{tabular}{|c|c|c|c|c|c|}
\hline \multirow{3}{*}{$\begin{array}{l}\text { Unidade da Federação / } \\
\text { Categoria Administrativa }\end{array}$} & \multirow{2}{*}{\multicolumn{5}{|c|}{ Matrículas em Cursos de Graduação Presenciais e a Distância-2015 }} \\
\hline & & & & & \begin{tabular}{|c|} 
Total Geral \\
\end{tabular} \\
\hline & Total & Bacharelado & Licenciatura & Tecnólogo & Não Aplicável \\
\hline Brasil & 8.027.297 & 5.516 .151 & 1.471 .930 & 1.010 .142 & 29.074 \\
\hline Pública & 1.952 .145 & 1.195 .020 & 578.997 & 149.209 & 28.919 \\
\hline Federal & 1.214 .635 & 800.417 & 323.295 & 68.862 & 22.061 \\
\hline Estadual & 618.633 & 301.873 & 233.222 & 76.699 & 6.839 \\
\hline Municipal & 118.877 & 92.730 & 22.480 & 3.648 & 19 \\
\hline Privada & 6.075 .152 & 4.321.131 & 892.933 & 860.933 & 155 \\
\hline
\end{tabular}

\begin{tabular}{|c|c|c|c|c|}
\hline \multirow{3}{*}{$\begin{array}{c}\text { Unidade da Federação / Categoria } \\
\text { Administrativa }\end{array}$} & \multicolumn{4}{|c|}{$\begin{array}{l}\text { Número de Concluintes em Cursos de Graduação } \\
\text { Presenciais e a Distância-2015 }\end{array}$} \\
\hline & \multicolumn{4}{|c|}{ Total Geral } \\
\hline & Total & Bacharelado & Licenciatura & Tecnólogo \\
\hline Brasil & 1.150 .067 & 680.665 & 237.818 & 231.584 \\
\hline Pública & 239.896 & 141.426 & 78.941 & 19.529 \\
\hline Federal & 134.447 & 87.529 & 39.391 & 7.527 \\
\hline Estadual & 86.770 & 40.884 & 34.930 & 10.956 \\
\hline Municipal & 18.679 & 13.013 & 4.620 & 1.046 \\
\hline Privada & 910.171 & 539.239 & 158.877 & 212.055 \\
\hline
\end{tabular}

Fonte: MECINEP/DEED http://portal. inep. gov.br/artigo/-/

\section{FUNDAMENTAÇÃO TEÓRICA}

O objetivo deste estudo é analisar e identificar a possibilidade de utilizar ferramentas da qualidade, entre elas as metodologias dos 5 Porquês, a Matriz de priorização e $5 \mathrm{~W} 2 \mathrm{H}$, para um melhor controle e comunicação entre tutores envolvidos na educação à distância e estudantes. E a partir deste objetivo traçar como metodologia, o desenvolvimento de um estudo de caso, realizado em uma Instituição com Cursos Superiores em EaD, em que se encontra a frequente evasão, e considerando todas as etapas em que ocorrem a evasão, ou seja, os que não iniciaram, os que abandonaram no decorrer e no final do curso.

A partir de dados coletados em informações oficiais, através do site do MEC/INEP/DEED e da própria ABED, foi observado como principal problema do ensino a distância, à evasão de estudantes por 4 anos consecutivos nas pesquisas.

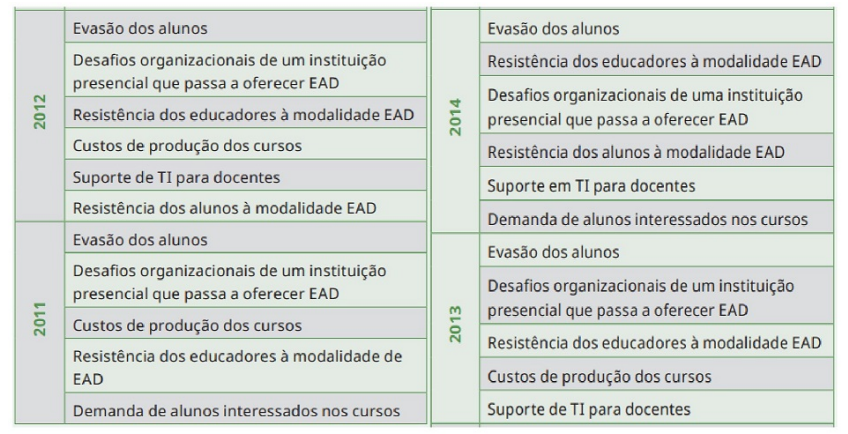

Fonte: Censo EAD Brasil 2016

Em segundo lugar no ano de 2014, como fator mais desafiador, está a resistência dos 
educadores em adaptar-se à modalidade, em terceiro aparecem as dificuldades de adaptação da educação presencial para $\mathrm{EaD}$ e, em quarto, a resistência dos alunos a este formato de ensino.

Através de um benchmarking, foram analisados dois aspectos: Um mercado concorrente, que mantém um contato mais frequente com os alunos, obtendo um relativo sucesso e equalizando a consistência de alunos nos cursos. E por outro lado a falta de interatividade dos envolvidos no processo de pertença dos alunos, motivando a evasão. E por se tratar de um método de ensino sem interação direta, professor aluno, uma linha frequente de evasão pode estar na falta de contato entre o tutor ou professor on line, pois ambos não estão acostumados a este novo formato de ensino, que necessita de maior interação pelos envolvidos. Na qualidade de prestador do serviço, muitas vezes o elo que marca presença nesta interação, se faz muito necessário, e o tutor ou professor on line seriam este elo, não como um suporte eventual, e sim permanente e frequente.

Apesar do curso ser realizado na modalidade a distância, o curso deve se preocupar principalmente em manter o aluno informado e bem assessorado com relação a metodologia, avaliações, atividades propostas, postagens etc., o tutor deve auxiliar o aluno no desenvolvimento de sua aprendizagem, mostrando as possibilidades e caminhos a serem percorridos, a modalidade é a distância, mas não deve existir essa distância entre o tutor e o estudante, ambos devem buscar desenvolver uma comunicação efetiva para o sucesso nos estudos, pois quanto mais próximo e informado o aluno estiver, melhor será seu aproveitamento no curso.

\section{METODOLOGIA}

Este estudo é de natureza qualitativa, de caráter exploratório e interpretativo, e tem como estratégia de pesquisa o estudo de caso. A seguir no quadro, apresentamos a situação em uma instituição hipotética, na qual observamos que o fator da evasão é presente pela falta de interação, além dos concorrentes estarem buscando resgatar esses alunos que se evadem das instituições, está se criando um mercado cada vez mais competitivo de matrículas no ensino a distância, que objetiva o maior número de matrículas, o que torna preocupante é a qualidade de ensino oferecida aos estudantes. 


\section{Aspecto no Mercado da EaD}

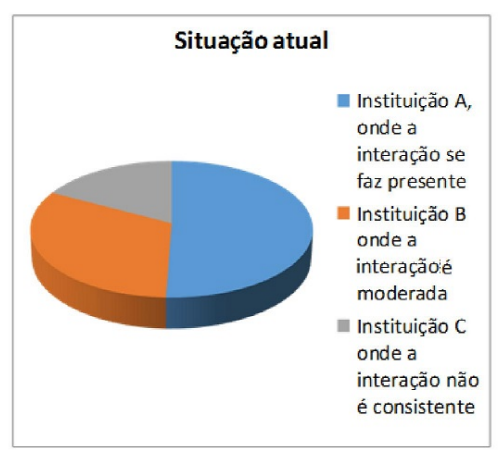

Fonte: Elaboradopelos atores, 2018
Com foco na qualidade e nas

melhorias para

uma gestão

adequada, 0

número de

alunos tende a

aumentar

perante a

concorrência que

esta mais ativa.

Com base no gráfico apresentado, realizamos alguns questionamentos, que podem ser melhor observados com a utilização da ferramenta dos 5 Porquês, (Oakland, 1994), que foi a técnica desenvolvida por Taiichi Ohno, (Corrêa, 2007). Ferramenta de simples compreensão e aplicação, podendo ser utilizada nas etapas inicias de praticamente qualquer plano de ação que vise à melhoria da qualidade. Como segue nossa análise.

Os alunos participam efetivamente das atividades do curso?

Para muitos alunos o fato de ser um Curso à distância, pode ser desinteressante se o tutor não se fizer presente, já que este é o principal contato do estudante do decorrer de seu processo de aprendizagem.

Deste modo, se torna fundamental, os avisos de alerta realizado periodicamente aos estudantes, destacando datas importantes para postagens, avaliações e chats, buscando nesse contato um melhor controle e monitoramento das atividades desenvolvidas no curso, ressaltando a importância de participação nas atividades propostas.

Porque os alunos não são contatados?

Frequentemente o papel do tutor é questionado, se deve apenas responder o aluno quando solicitado ou se ele deve estar em constante contato com os alunos.

Os tutores devem realizar contatos mais frequentes, todavia se a margem de alunos que participam das atividades diminuir ou os que estão apresentando dificuldades aumentarem, seria um bom motivo para entrar em ação. Fazer-se presente poderia ser uma forma de atrair esta parcela que muitas vezes se sente confusa com a metodologia de estudo. 
Porque há grande evasão de alunos?

$\mathrm{Na}$ realidade esta resposta pode ter várias fontes e fatores influenciadores, como fatores financeiros, desinteresse pelo tema, falta de acompanhamento e orientação, etc. Realmente a análise periódica do número de alunos que compõe os cursos deve ser monitorada frequentemente. Esta análise realizada através da utilização das ferramentas da qualidade, pode contribui para que os números de evadidos diminuam, no sentido de estar à frente dos possíveis resultados, e para que a instituição possa entrar em contato com o aluno e sanar as dificuldades e problemas apresentados.

Porque que esperamos que a evasão ocorra?

Muitas vezes a equipe que compõe a EaD é formada por professores ou profissionais acostumados com o sistema tradicional de ensino, no qual o contato é direto com o aluno, observamos aí uma certa resistência ao novo formato, já que não há nenhum contato físico. Além da resistência a esta metodologia de ensino, não podemos deixar de citar que os docentes hoje atuantes da $\mathrm{EaD}$, receberam uma formação tradicional e que muitas vezes buscam reproduzi-las através das tecnologias. São atuantes e preparados para atuar de forma corretiva, e o se busca na EaD é uma atuação preventiva.

Porque não estou conseguindo desenvolver e acompanhar os objetivos propostos no curso?

Acreditar que se tem uma metodologia adequada sem mesmo analisar os possíveis erros, pode trazer um grande problema para o futuro do curso.

Estar em constante treinamento e atualização podem ser as ferramentas para o sucesso. É necessário questionar o público-alvo para uma abordagem mais acentuada.

Contando com uma equipe treinada seria possível atender este público, através do contato com o aluno para identificação das dificuldades, buscando soluções e uma relação próxima com o estudante, buscando diminuir a distância e dificuldades existentes, assim tentando resgatar o estudante para sua formação e evitando com isso a evasão.

No processo de ensino, a formação da equipe é de vital importância, pois nesta cadeia de serviços, deixar de saber a opinião do cliente, "o aluno", pode ser crucial e fundamental para evitar a falta de interesse deste pelo curso, podendo não haver mais 
tempo de recuperar o cliente. Afinal com uma estrutura formada por Tutores e Coordenadores, estes devem marcar presença no processo, e não aguardar serem chamados ao trabalho.

O tutor deve ser o elo entre o aluno e o curso EaD, deve procurar saber quais as dificuldades e opiniões dos estudantes para que este possa buscar desenvolver e aplicar em seu trabalho, contribuindo para o bom desenvolvimento do curso, esse interesse pode ser a diferença para o sucesso do curso. Deste modo, apresentamos abaixo, um fluxograma ideal de atendimento no ensino a distância.

Fluxograma ideal no processo de tutoria na EaD:

- Início do curso: No contato com o aluno apresentar as metas e objetivos;

- Tutor estar à disposição: Alertar o aluno quanto a avaliações, prazos e datas para postagens;

- No contato com o aluno: As possíveis dúvidas devem ser repassadas imediatamente à coordenação ou responsáveis;

- Avaliação do curso: Verificar se deve ser alterado algo no processo avaliativo, assim como materiais fornecidos;

- Final do curso: Fazer-se presente para que todos os alunos estejam no mesmo nível e com sentimento de pertença na instituição.

Nesse processo, é importante observar que:

Com uma adequação no processo, podemos reverter o quadro da evasão, reorganizando e reestruturando a matriz de priorização. Levando em conta uma boa gestão na prestação de um serviço, objetivando um serviço de qualidade com produtividade e lucratividade. A equipe deste processo deve estar adequada e alinhada as metas e objetivos. Com base na matriz priorização (Lucinda, 2010), foi desenvolvido um plano de ação para acompanhar o desenvolvimento e buscar reduzir a evasão presente nos cursos EaD.

Reduzir e corrigir as falhas é primordial para um bom desempenho da instituição. 


\begin{tabular}{|c|c|c|c|c|c|}
\hline & Gravidade & Urgência & Tendência & Soma & Prioridade \\
\hline $\begin{array}{l}\text { O não contato com o } \\
\text { aluno }\end{array}$ & 5 & 8 & 9 & 22 & $7^{\mathrm{a}}$ \\
\hline $\begin{array}{l}\text { A não atualização de } \\
\text { notas }\end{array}$ & 7 & 7 & 7 & 21 & $8^{a}$ \\
\hline $\begin{array}{l}\text { Informação } \\
\text { desatualizada }\end{array}$ & 10 & 9 & 9 & 28 & $2^{\mathrm{a}}$ \\
\hline Demora no contato & 9 & 8 & 9 & 26 & $3^{a}$ \\
\hline Não orientar o aluno & 9 & 9 & 5 & 23 & $6^{\mathrm{a}}$ \\
\hline $\begin{array}{l}\text { Centralizar } \\
\text { informações }\end{array}$ & 6 & 5 & 4 & 15 & $9^{a}$ \\
\hline Baixa no $n^{\circ}$ de alunos & 9 & 10 & 10 & 29 & $1^{\mathrm{a}}$ \\
\hline $\begin{array}{l}\text { O não Feedback aos } \\
\text { alunos }\end{array}$ & 8 & 9 & 8 & 25 & $4^{a}$ \\
\hline $\begin{array}{l}\text { Não motivar e atrair } \\
\text { o aluno }\end{array}$ & 7 & 9 & 8 & 24 & $5^{\mathrm{a}}$ \\
\hline
\end{tabular}

Fonte: Elaborado pelos autores, 2018

O Plano de Ação foi elaborado através da ferramenta 5W 2H (Lucinda ,2010), onde questiona-se os porquês $(\mathrm{W})$ e como $(\mathrm{H})$, enfatizar uma melhora no sistema. Esta ferramenta é útil em duas situações distintas de análise: na verificação das ocorrências de um problema e na elaboração de um plano de ação. Percebe-se que ao se fazer as perguntas, estas podem sofrem pequenos ajustes na temporalidade, porém, o objetivo principal de cada uma delas continua o mesmo.

\begin{tabular}{|l|l|}
\hline Objetivo & Reduzir a evasão de alunos dos Cursos EaD \\
\hline O que fazer & Rever formas de contato antecipando-se ao problema \\
\hline Onde fazer & No sistema de Tutoria e Coordenação \\
\hline Porque fazer & A baixa de alunos traz falta de credibilidade e qualidade \\
\hline Como fazer & Acentuando responsabilidades no processo \\
\hline Quem deve fazer & $\begin{array}{l}\text { Os profissionais que devem ser mais atuantes, ativos e presentes a } \\
\text { metodologia }\end{array}$ \\
\hline Quando fazer & A partir da formação das turmas nos Cursos. \\
\hline Quanto custa fazer & $\begin{array}{l}\text { Com o sistema atual um controle acentuado e treinamento adequado } \\
\text { aos envolvidos, baixo custo. }\end{array}$ \\
\hline Fonte: Elaboradopplos attores, 2018 &
\end{tabular}

\section{FATORES DETERMINANTES NA MELHORIA}

1. Conforme apresentado, a nova implantação do programa agrega interação, adequando a equipe ao procedimento adequado com os alunos;

2. Na implementação de certos procedimentos, os quais não tem custo excessivo ao processo, pode-se reverter o quadro;

3. Como conclusão, deve-se priorizar a presença do tutor buscando um maior contato com o aluno, desenvolvendo um elo importante de ação, atração e qualidade.

Ao adequar a nova sistemática, será percebida a necessidade de um treinamento específico com a equipe interdisciplinar, para um melhor aproveitamento na capacidade de relacionamento e contato com o aluno. Pois desta forma os envolvidos contribuem para que o aluno da educação a distância, tenha sentimento de pertença a instituição, 
reconhecendo que seus suportes ou envolvidos no apoio, estarão presentes para reduzirem o sentimento de solidão dos cursos à distância.

E com este padrão a ser implantando poderá ser observado algumas vantagens como destacado nos tópicos a seguir.

Para a reformulação da sistemática do ensino, investir em um treinamento frequente seria a solução, haver necessidade de ampliar o quadro funcional apenas a partir do aumento de ofertas de cursos, para adequar com mais qualidade o contato com os estudantes.

Para a implementação destas mudanças não haveria um grande custo, pois, o quadro de pessoas envolvidas é suficiente para o início do projeto.

Para um bom desempenho financeiro a análise foi feita nas perdas de oportunidades de crescimento. Estas oportunidades com a proposta de adequação serão relativamente sentidas com a redução na evasão dos alunos nos cursos ofertados.

Um dos principais pontos analisados é a falta de comprometimento dos envolvidos, tanto por parte do corpo docente quanto dos alunos.

Se o treinamento não for correspondido pela equipe treinada, a implantação do novo sistema estará comprometida.

Melhorando o sistema de interação entre aluno e a instituição, faz com que a evasão diminua, a qualidade dos serviços prestados aumente, proporcionando um maior interesse da sociedade no ensino EaD, e desta maneira a lucratividade tende a aumentar.

O impacto causado por esta mudança vai incentivar maiores investimentos neste setor criando novas instituições, que acabarão por dar mais oportunidades para um número maior de futuros alunos.

\section{CONSIDERAÇÕES FINAIS}

Como o estudo foi baseado na comparação de dados coletados por tabelas e gráficos disponibilizados por envolvidos no tema, devemos deixar claro que a conclusão deve define-se em uma proposta, pois como está calçada em diversas bibliografias direcionadas na implantação de ferramentas da qualidade nos processos, e que todos 
sugerem sempre que as oportunidades de implantação de sistemas de qualidade assim como a utilização destas ferramentas surtiram efeitos positivos.

Quando identificamos os possíveis problemas, e buscamos soluções; constatamos que a qualidade esperada no processo apresentado, aumenta.

E por assim dizer neste estudo, com todas as propostas apresentadas a produtividade aumenta a lucratividade na Instituição, e com isso percebemos uma maior satisfação do cliente, "o aluno", com relação a mesma buscando sempre melhorias para o cliente.

\section{REFERÊNCIAS}

ABED - Associação Brasileira e Educação à Distância

ARAÚJO JÚNIOR, Carlos Fernando de - Desafios da Educação a Distância: inovação e institucionalização - São Paulo - Terracota Editora, 2016.

CORRÊA, Henrique L. - Administração de produção e operações: manufatura e serviços: uma abordagem estratégica /Henrique L. Corrêa, Carlos A. Corrêa. $2^{\mathrm{a}}$ Ed. São Paulo - Atlas, 2007

LUCINDA, Marco Antônio. Qualidade: fundamentos e práticas para cursos de graduação. Rio de janeiro: Brasport, 2010.

MEC/INEP/DEED - http://portal.inep.gov.br/

OAKLAND, John - Gerenciamento da qualidade total - (Tradução Adalberto Guedes Pereira) - São Paulo - Nobel, 1994.

SELEME, Robson e STADLER, Humberto. Controle da Qualidade: as ferramentas essenciais. Curitiba: Ibpex, 2008

SMITH, G.F. Quality Problem Solving. Milwaukee: ASQ Quality Press, 1998.

ZAWACKI-RICHTER, Olaf e Terry Anderson - Educação a distância online: construindo uma agenda de pesquisa - 1. ed. -- São Paulo: Artesanato Educacional, 2015. 